\title{
Sulfonation of chlorinated polypropylene and its influence on the microstructure and the electric properties of polypropylene/chlorinated polypropylene/polyaniline composites
}

\author{
Lin Yang ${ }^{1,2}$, Zhiye Zhang ${ }^{1}$, Xinlong Wang ${ }^{1}$, Jinyao Chen ${ }^{2}$ and Huilin $\mathrm{Li}^{2}$
}

Sulfonated $\mathrm{CPP}\left(\mathrm{CPP}-\mathrm{SO}_{3} \mathrm{H}\right)$ was prepared by modifying chlorinated polypropylene (CPP). The results of Fourier transform infrared spectroscopy (FTIR) illustrate that the sulfonic acid group $\left(-\mathrm{SO}_{3} \mathrm{H}\right)$ was successfully grafted onto CPP. Polypropylene (PP)/CPP-SO ${ }_{3} \mathrm{H} /$ polyaniline (PANI) and PP/CPP/PANI composites were prepared, and the microstructures and electric properties of the corresponding composites were carefully investigated by scanning electron microscopy (SEM), FTIR, ultraviolet (UV)-vis and wide-angle X-ray diffraction (WAXD). Compared with that of the PP/CPP/PANI composite, the volume resistivity of the $\mathrm{PP} / \mathrm{CPP}-\mathrm{SO}_{3} \mathrm{H} / \mathrm{PANI}$ composites is lower. The UV-vis results show that PANI can be doped with $\mathrm{CPP}-\mathrm{SO}_{3} \mathrm{H}$ and that the interactional strength between PANI and $\mathrm{CPP}-\mathrm{SO}_{3} \mathrm{H}$ increases because of the introduction of $-\mathrm{SO}_{3} \mathrm{H}$. The results of WAXD show that $\mathrm{CPP}-\mathrm{SO}_{3} \mathrm{H}$ is more easily inserted into the interspaces of PANI-dodecylbenzene sulfonic acid and makes the layer distance increase compared with that of CPP. The addition of $\mathrm{CPP}-\mathrm{SO}_{3} \mathrm{H}$ can improve the crystallinity of the composites. The results of SEM show that the introduction of $-\mathrm{SO}_{3} \mathrm{H}$ on CPP is favorable for dispersion of PANI in the PP/CPP-SO ${ }_{3} \mathrm{H} / \mathrm{PANI}$ composites, and that it results in an increase in the area of the conducting components, an improvement in conductive properties and the compatibility of the PP/CPP- $\mathrm{SO}_{3} \mathrm{H} / \mathrm{PANI}$ composites. The above results indicate that $\mathrm{CPP}-\mathrm{SO}_{3} \mathrm{H}$ can act as PANI's doping agent and facilitate compatibility in PP/CPP- $\mathrm{SO}_{3} \mathrm{H} / \mathrm{PANI}$ composites.

Polymer Journal (2012) 44, 388-395; doi:10.1038/pj.2011.139; published online 18 January 2012

Keywords: chlorinated polypropylene; composite; polyaniline; polypropylene; sulfonation

\section{INTRODUCTION}

Conductive polymers are expected to yield attractive combinations of properties and are gaining increasing attention from researchers worldwide. For many years, researchers have been using these polymers to produce electronic materials, ${ }^{1-3}$ particularly antistatic materials, sensor materials ${ }^{4-6}$ and anticorrosive coatings. ${ }^{7-9}$ Among conductive polymers, polyaniline (PANI) has the best potential to become economically competitive because of its inexpensive materials, ease of synthesis, environmental stability ${ }^{10}$ and high electrical conductivity, which can be reversibly controlled by a change in the oxidation state and protonation of the imine nitrogen groups. ${ }^{11}$

Although PANI has many merits, it is difficult to process using conventional polymer-based methods because of its strong intermolecular and intramolecular interactions. ${ }^{12}$ Many new protonating agents, such as sulfonic acids, phosphoric acid esters ${ }^{12,13}$ and phosphoric acids, ${ }^{14}$ have been introduced in recent years to improve the processability of PANI. Cao et al. ${ }^{15}$ first introduced sulfonic acid as a protonating agent, which made it possible to process PANI in a solvent. Another method developed to improve the processability of PANI is the blending of PANI with thermoplastic polymers due to PANI's poor mechanical properties. ${ }^{14,16-18} \mathrm{~A}$ unique advantage of this method lies in the combination of the electrical properties of PANI and mechanical properties of thermoplastic polymers.

In previous studies, ${ }^{19,20}$ we have investigated the possibility of melt processing polypropylene (PP)/chlorinated polypropylene (CPP)/ PANI composites and have shown that CPP has a prominent role in determining the composite's electrical properties. We also investigated the effects of CPP on the formation of the intermolecular and intramolecular hydrogen bonds in PP/CPP/PANI composites through Fourier transform infrared spectroscopy (FTIR). The obtained results show that the introduction of CPP weakens the intermolecular and intramolecular $\mathrm{H}$ bond of PANI-dodecylbenzene sulfonic acid (DBSA), which is substituted by the intermolecular H-bond interaction between CPP and PANI-DBSA, and promotes the dispersion of PANI-DBSA and a decrease in the volume resistivity of the composites. 
The intermolecular H-bond interaction between CPP and PANIDBSA through the $\mathrm{H}$-bond $\mathrm{N}-\mathrm{H} \cdots \cdots \mathrm{Cl}$ is weak. Therefore, improvement in the dispersion of PANI-DBSA is limited. In this study, the sulfonic acid group $-\mathrm{SO}_{3} \mathrm{H}$ was introduced into CPP. As sulfonic acid can act as a protonating agent of PANI, the interaction between modified CPP and PANI may be stronger than that between CPP and PANI, and modified CPP may further improve dispersion of PANI in the composite. In this study, the influence of modified CPP on the electrical properties, morphology and microstructure of the composites was carefully analyzed by methods such as FTIR, wide-angle Xray diffraction (WAXD) and scanning electron microscopy (SEM).

\section{EXPERIMENTAL PROCEDURE}

\section{Materials}

Polyaniline protonated with hydrochloric acid $(\mathrm{HCl})$ was supplied by Chengdu Organic Chemicals (Chengdu, China); its electrical conductivity was $\sim 1 \mathrm{~S} \mathrm{~cm}^{-1}$.

Polypropylene (PPH-XD-045, melt-flow index $=3.5 \mathrm{~g}$ per $10 \mathrm{~min}$ ) was supplied by PetroChina (Lanzhou, China).

Dodecylbenzene sulfonic acid was supplied by Kewei Chemicals (Chengdu, China), and its content was 96\% (wt).

Chlorinated polypropylene was supplied by Sichuan Weiye Chemicals (Chengdu, China). Its chlorine content was $\sim 31 \%$ (wt) and appeared yellow. The molecular weight of CPP was not clear. The viscosity of $20 \%$ (wt) of CPP in toluene solution was $\sim 700 \mathrm{mPa} . \mathrm{s}$ at $25^{\circ} \mathrm{C}$.

Sodium bisulfite $\left(\mathrm{NaHSO}_{3}\right)$, xylene (mixture), potassium hydroxide $(\mathrm{KOH})$, acetic acid $\left(\mathrm{CH}_{3} \mathrm{COOH}\right)$, ethanol $\left(\mathrm{CH}_{3} \mathrm{CH}_{2} \mathrm{OH}\right)$, phenolphthalein, barium chloride anhydrous $\left(\mathrm{BaCl}_{2}\right)$ and $\mathrm{HCl}$ were analytical reagents supplied by Kelong Chemicals (Chengdu, China).

\section{Preparation of composites}

Sulfonation of CPP. Modification of CPP was carried out in a 500-ml threenecked flask equipped with a condenser. In all, $50 \mathrm{~g}$ CPP and $125 \mathrm{ml}$ xylene were placed into the flask under stirring for $1 \mathrm{~h} \mathrm{at} 80^{\circ} \mathrm{C}$, and then $90 \mathrm{~g}$ of $\mathrm{NaHSO}_{3}$ solution $(33.3 \% \mathrm{wt})^{21,22}$ was dropped into the reactor. The reaction was allowed to proceed for $24 \mathrm{~h}$ at $100^{\circ} \mathrm{C}$ and then cooled to ambient temperature. Overall, $36 \mathrm{~g} \mathrm{HCl}$ was dropped into the reactor under stirring for $0.5 \mathrm{~h}$. A large amount of distilled water was placed into the flask and allowed to stand for $24 \mathrm{~h}$; the modified CPP was then separated from water. This procedure was repeated several times until there was no precipitation when the $\mathrm{BaCl}_{2}$ solution (10\% wt) was dropped into the separated water. The product was dried in a vacuum at $50^{\circ} \mathrm{C}$. Finally, sulfonated $\mathrm{CPP}\left(\mathrm{CPP}-\mathrm{SO}_{3} \mathrm{H}\right)$ was obtained. The following is a schematic diagram of the sulfonation of CPP.

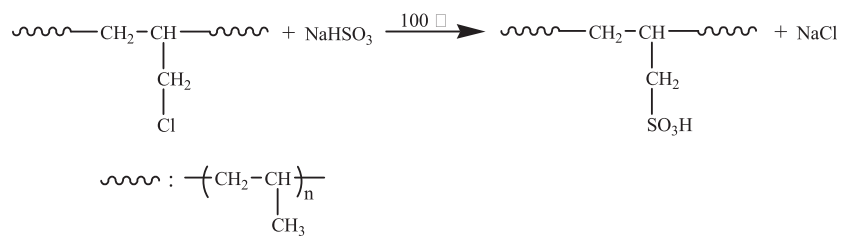

Protonation of PANI with DBSA. Polyaniline protonated with $\mathrm{HCl}$ was neutralized with $20 \%$ (wt) sodium hydroxide $(\mathrm{NaOH})$ aqueous solution for
$48 \mathrm{~h}$ and then filtered and washed with deionized water until the $\mathrm{pH}$ value of the percolate was $6-8$. The obtained polyemeraldine base $\left(\mathrm{PANI}_{\text {emer }}\right)$ was dried under vacuum. Purified and dried PANI ${ }_{\text {emer }}$ was blended with DBSA, and the molar ratio of DBSA to $\mathrm{PANI}_{\text {emer }}$ was 0.5 . The blend was stirred for $48 \mathrm{~h}$ at ambient temperature, thus producing PANI protonated with DBSA (PANIDBSA).

Preparation of PP/PANI composites. The composites of PP/PANI with different $\mathrm{CPP}$ or $\mathrm{CPP}-\mathrm{SO}_{3} \mathrm{H}$ contents were prepared on a two-roll mill and then molded into 1-mm plates. Compression molding was carried out under the following conditions: preheated at $180^{\circ} \mathrm{C}$ for $5 \mathrm{~min}$ at low pressure, compressed for $10 \mathrm{~min}$ at $13 \mathrm{MPa}$ at the same temperature and then cooled to ambient temperature at the cooling rate of $30^{\circ} \mathrm{C}$ per min in the mold at $13 \mathrm{MPa}$. Specimens with dimensions of $80 \times 80 \times 1 \mathrm{~mm}^{3}$ were obtained from the $1-\mathrm{mm}$ plates to test their volume resistivity. The blend compositions and their corresponding sample codes are listed in Table 1.

\section{Measurement of volume resistivity}

Volume resistivity of the composites was detected using a high-resistance meter (ZC46A) produced by the Shanghai Precision Scientific Instrument (Shanghai, China). The result of each sample is the average of four measurements.

\section{Scanning electron microscope}

A JSM 5900 LV scanning electron microscope (SEM; JEOL, Tokyo, Japan) was used to observe the morphology of the PP/CPP/PANI composites. The specimens were cut from the 1-mm plates using a very sharp knife and then polished using a special polisher. By not sputtering the SEM samples with a thin conducting layer, it was possible to show the contrast between the electrically conductive and insulating parts of the material. ${ }^{19}$ The SEM images of nonsputtered samples are not based on real material contrast, but result from a contrast in the electrical conductivity between the electrically conductive fillers and insulating matrix. ${ }^{23}$

\section{Wide-angle X-ray diffraction}

Wide-angle X-ray diffraction measurements were carried out using a DX-2500 SSC diffractometer (Fangyuan, Dandong, China) in reflection mode. $\mathrm{Cu} \mathrm{K \alpha}$ radiation was used at $40 \mathrm{kV}$ and $25 \mathrm{~mA}$. Investigations were performed using two methods. First, in the range of angles $2-5^{\circ}$, the scan step was $0.03^{\circ}$ (in $2 \theta$ ) with a counting time of $4 \mathrm{~s}$ per step. Second, in the range of angles $5-45^{\circ}$, the scan step was $0.06^{\circ}$ (in $2 \theta$ ), with a counting time of $2 \mathrm{~s}$ per step.

To determine the mass fraction of crystallinity, WAXD curves were deconvoluted into crystalline and amorphous scattering components using the profile-fitting program JADE 6.5 (Materials data, Inc., Livermore, CA, USA). Each peak was modeled using a Gaussian-Cauchy peak shape. The degree of crystallinity was determined as the ratio of the areas of all crystalline peaks to that of total scattering. WAXD patterns were also used to evaluate the mean sizes of the crystallites. The crystallite size was estimated for planes of PP by using the Scherrer equation:

$$
D=K \lambda /(\beta \cos \theta)
$$

where $D$ is the crystallite size along the direction perpendicular to the plane, $\beta$ the full-width at half-maximum, the wavelength $\lambda=0.154 \mathrm{~nm}$ and $\theta$ the Bragg angle (half of the scattering angle). ${ }^{14}$

Table 1 Composition of PP/CPP/PANI and PP/CPP-SO ${ }_{3} \mathrm{H} / \mathrm{PANI}$ composites (in wt)

\begin{tabular}{|c|c|c|c|c|c|c|}
\hline Sample code & $P P \%$ & $P A N I_{e m e r} \%$ & $D B S A \%$ & CPP\% & $\mathrm{CPP}-\mathrm{SO}_{3} \mathrm{H} \%$ & Ratio $\frac{P P}{P A N I-D B S A}$ \\
\hline PP/CPP/PANI 0 & 83.70 & 4.10 & 7.79 & 4.41 & 0 & 7.04 \\
\hline $\mathrm{PP} / \mathrm{CPP}-\mathrm{SO}_{3} \mathrm{H} / \mathrm{PANI} 1$ & 87.22 & 4.10 & 7.79 & 0 & 0.88 & 7.34 \\
\hline $\mathrm{PP} / \mathrm{CPP}-\mathrm{SO}_{3} \mathrm{H} / \mathrm{PANI} 2$ & 86.34 & 4.10 & 7.79 & 0 & 1.76 & 7.26 \\
\hline $\mathrm{PP} / \mathrm{CPP}-\mathrm{SO}_{3} \mathrm{H} / \mathrm{PANI} 3$ & 85.46 & 4.10 & 7.79 & 0 & 2.64 & 7.19 \\
\hline $\mathrm{PP} / \mathrm{CPP}-\mathrm{SO}_{3} \mathrm{H} / \mathrm{PANI} 4$ & 83.70 & 4.10 & 7.79 & 0 & 4.41 & 7.04 \\
\hline $\mathrm{PP} / \mathrm{CPP}-\mathrm{SO}_{3} \mathrm{H} / \mathrm{PANI} 5$ & 82.60 & 4.10 & 7.79 & 0 & 5.51 & 6.95 \\
\hline
\end{tabular}

Abbreviations: CPP, chlorinated polypropylene; PANI, polyaniline; PP, polypropylene. 


\section{FTIR measurement}

Specimens used for FTIR measurement were prepared by two methods. Specimens of the PP/CPP/PANI and PP/CPP-SO ${ }_{3} \mathrm{H} / \mathrm{PANI}$ composites for FTIR measurement were molded into very thin films. Compression molding was carried out under the following conditions: samples were preheated at $180^{\circ} \mathrm{C}$ for $5 \mathrm{~min}$ at low pressure, compressed for $10 \mathrm{~min}$ at $15 \mathrm{MPa}$ at the same temperature and then cooled to ambient temperature at a cooling rate of $30^{\circ} \mathrm{C}$ per min in the mold at $15 \mathrm{MPa}$. $\mathrm{CPP}$ or $\mathrm{CPP}-\mathrm{SO}_{3} \mathrm{H}$ was dissolved by xylene, and the solutions were then cast into very thin films. Finally, the films were dried in a vacuum at $50{ }^{\circ} \mathrm{C}$. FTIR analysis of specimens was conducted with a Nicolet $170 \times$ FTIR spectrometer (Nicolet, Barrington, WI, USA).

\section{Sulfonating degree measurement}

Neutralization titration was adopted to measure the degree of sulfonation of the specimens. Approximately $0.5 \mathrm{~g}$ of each specimen was weighed using an analytical balance, and $100 \mathrm{ml}$ of xylene was placed into a conical flask with a condenser under stirring for $1.5 \mathrm{~h}$ at $140{ }^{\circ} \mathrm{C}$. When the flask was cooled to $50^{\circ} \mathrm{C}$, a superfluous $\mathrm{KOH}-\mathrm{CH}_{3} \mathrm{CH}_{2} \mathrm{OH}$ titrating solution was placed into the flask under stirring. The reaction was allowed to proceed for $0.5 \mathrm{~h}$ at $50^{\circ} \mathrm{C}$ and was then titrated with a $\mathrm{CH}_{3} \mathrm{COOH}$-xylene solution, and with a solution of phenolphthalein- $\mathrm{CH}_{3} \mathrm{CH}_{2} \mathrm{OH}$ that was used as an indicator. The degree of sulfonation is the ratio of the number of $-\mathrm{SO}_{3} \mathrm{H}$ groups in $\mathrm{CPP}-\mathrm{SO}_{3} \mathrm{H}$ to the number of chlorine atoms in $\mathrm{CPP}$ and is calculated by the following formula.

$$
S=2 \times 35.5 \times \frac{\left(C_{1} V_{1}-C_{2} V_{2}\right)-N_{0}}{0.31 \times 1000}
$$

$C_{1}$ and $C_{2}$ are the concentrations of the titrating solution of $\mathrm{KOH}$ and $\mathrm{CH}_{3} \mathrm{COOH}$, respectively $\left(\mathrm{moll}^{-1}\right) . V_{1}$ and $V_{2}$ are the volumes of the titrating solutions of $\mathrm{KOH}$ and $\mathrm{CH}_{3} \mathrm{COOH}$, respectively $(\mathrm{ml})$, which were placed into the flask. $N_{0}$ is the number of $\mathrm{KOH}$ molecules (mol) consumed by CPP.

\section{UV-vis measurement}

$\mathrm{PP} / \mathrm{CPP} / \mathrm{PANI}$ and $\mathrm{PP} / \mathrm{CPP}-\mathrm{SO}_{3} \mathrm{H} / \mathrm{PANI}$ composite specimens used for ultraviolet (UV)-vis measurement were molded into very thin films. Compression molding was carried out under the following conditions: specimens were preheated at $180{ }^{\circ} \mathrm{C}$ for $5 \mathrm{~min}$ at low pressure, compressed for $10 \mathrm{~min}$ at $15 \mathrm{MPa}$ at the same temperature and then cooled to ambient temperature at a cooling rate $30^{\circ} \mathrm{C}$ per min in the mold at $15 \mathrm{MPa}$. The UV-vis analysis of specimens was conducted using a Hitachi U-3010 spectrometer (Hitachi, Tokyo, Japan).

\section{RESULTS AND DISCUSSION}

\section{Characterization of the modified CPP}

Figure 1 shows the FTIR spectra of CPP and modified CPP (the sulfonating degree is $1.53 \%$ ). In spectrum (a), the band at $2957 \mathrm{~cm}^{-1}$ is attributed to C-H stretching, and the band at $738 \mathrm{~cm}^{-1}$ is attributed to $\mathrm{C}-\mathrm{Cl}$ stretching. Compared with spectrum (a), spectrum (b) shows a new strong absorption band at $\sim 1150 \mathrm{~cm}^{-1}$, which is attributed to the stretching band of $-\mathrm{SO}_{3} \mathrm{H} .{ }^{24}$ Thus, it can be seen that the $-\mathrm{SO}_{3} \mathrm{H}$ group has been successfully grafted onto CPP and the method of sulfonation adopted in this study is feasible.

\section{The volume resistivity of the $\mathrm{PP} / \mathrm{CPP}-\mathrm{SO}_{3} \mathrm{H} / \mathrm{PANI}$ and $\mathrm{PP} / \mathrm{CPP} /$ PANI composites}

Figure 2 shows the volume resistivity of the PP/CPP-SO ${ }_{3} \mathrm{H} / \mathrm{PANI}$ and $\mathrm{PP} / \mathrm{CPP} / \mathrm{PANI}$ composites. In the $\mathrm{PP} / \mathrm{CPP}-\mathrm{SO}_{3} \mathrm{H} / \mathrm{PANI}$ composites, the degree of sulfonation of $\mathrm{CPP}-\mathrm{SO}_{3} \mathrm{H}$ is $1.53 \%$. Volume resistivity first decreases with increasing $\mathrm{CPP}-\mathrm{SO}_{3} \mathrm{H}$ content and reaches a minimum volume resistivity when the $\mathrm{CPP}-\mathrm{SO}_{3} \mathrm{H}$ content is lower than $4.41 \%$; volume resistivity then increases with a further increase in the $\mathrm{CPP}-\mathrm{SO}_{3} \mathrm{H}$ content.

In Figure 2, the sample without added $\mathrm{CPP}-\mathrm{SO}_{3} \mathrm{H}$ is marked as $\mathrm{PP} / \mathrm{CPP} / \mathrm{PANI} 0$, and its CPP content is $4.41 \%$. The content of PANI is the same in the two kinds of composites. However, compared with the

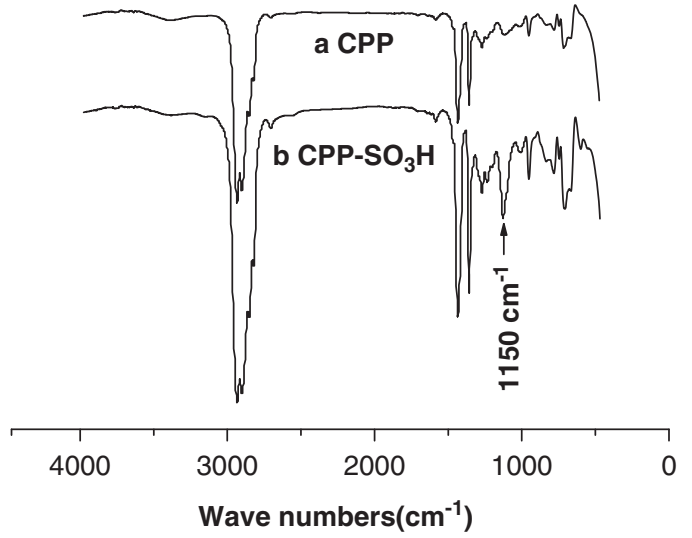

Figure 1 FTIR spectra of CPP and modified CPP. CPP, chlorinated polypropylene; FTIR, Fourier transform infrared spectroscopy.

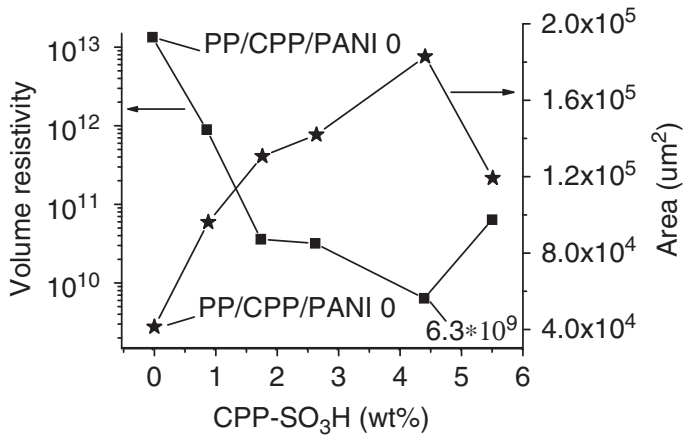

Figure 2 Relationship between the area of the conducting regions and the volume resistivity change with $\mathrm{CPP}-\mathrm{SO}_{3} \mathrm{H}$ content. $\mathrm{CPP}$, chlorinated polypropylene.

$\mathrm{PP} / \mathrm{CPP} / \mathrm{PANI} 0$ composite, the volume resistivity of the PP/CPP$\mathrm{SO}_{3} \mathrm{H} / \mathrm{PANI}$ composites is lower, and that of the PP/CPP-SO ${ }_{3} \mathrm{H} / \mathrm{PANI}$ 4 composite decreases by four orders of magnitudes, which suggests that the introduction of $-\mathrm{SO}_{3} \mathrm{H}$ into $\mathrm{CPP}$ can effectively reduce the volume resistivity of the composite.

\section{FTIR spectra of the PP/CPP-SO 3 H/PANI and PP/CPP/PANI composites}

Figure 3a shows the FTIR spectra of the PP/CPP/PANI and PP/CPP$\mathrm{SO}_{3} \mathrm{H} / \mathrm{PANI}$ composites. Compared with the spectrum of the $\mathrm{PP} / \mathrm{CPP} /$ PANI composite, there are several altered bands in the spectrum of the $\mathrm{PP} / \mathrm{CPP}-\mathrm{SO}_{3} \mathrm{H} / \mathrm{PANI}$ composites, such as the $\mathrm{N}-\mathrm{H}$ stretching region $\left(3320-3600 \mathrm{~cm}^{-1}\right)$ and the region between 1110 and $1140 \mathrm{~cm}^{-1}$. The variation of these bands indicates that the introduction of $-\mathrm{SO}_{3} \mathrm{H}$ into CPP influences the intermolecular or intramolecular interactions of the PP/CPP/PANI composite, which will be discussed in detail according to FTIR analysis in the following sections.

The region between 3320 and $3600 \mathrm{~cm}^{-1}$ is attributed to PANI's $\mathrm{N}-\mathrm{H}$ stretching region, ${ }^{25}$ and no band is found in this region of the FTIR spectra of PP or CPP. As the PANI emer $_{\text {content is only } 4.10 \%(\mathrm{w} /}$ $\mathrm{w}$ ) in the composites, these bands are not particularly distinct in Figure 3a. The amplified bands of this region are presented in Figure $3 \mathrm{~b}$.

As shown in Figure 3b, there are at least two distinct bands. One band, at $\sim 3345 \mathrm{~cm}^{-1}$, is attributed to the hydrogen-bonded 

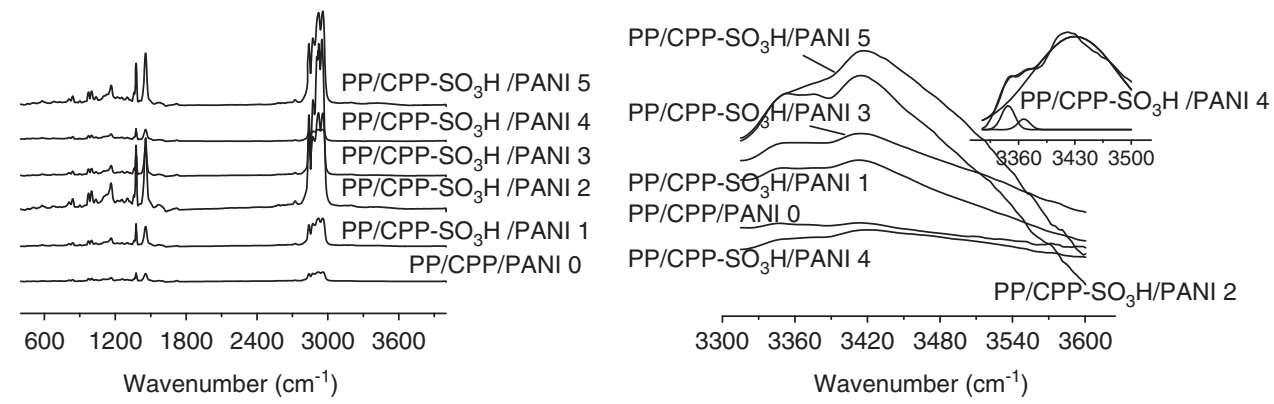

Figure $3 \mathrm{FTIR}$ spectra of the (a) PP/CPP/PANI and (b) PP/CPP-SO ${ }_{3} \mathrm{H} / \mathrm{PANI}$ composites in two wave number ranges. CPP, chlorinated polypropylene; FTIR, Fourier transform infrared spectroscopy; PANI, polyaniline; PP, polypropylene.

Table 2 Curve-fitting results for the $\mathrm{N}-\mathrm{H}$ stretching region

\begin{tabular}{|c|c|c|c|c|c|c|c|}
\hline Sample code & \multicolumn{3}{|c|}{$H$-bonded $\mathrm{N}-\mathrm{H} \mathrm{N}-\mathrm{H} \cdots \mathrm{O}$} & $v 2 \mathrm{~cm}^{-1}$ & \multicolumn{3}{|c|}{$\begin{array}{c}H \text {-bonded } \mathrm{N}-\mathrm{H} \\
\mathrm{N}-\mathrm{H} \cdots N \\
\mathrm{~N}-\mathrm{H} \cdots \mathrm{Cl}\end{array}$} \\
\hline PP/CPP/PANI 0 & 3344.8 & 17.8 & 0.021 & 3368.7 & 3413.9 & 30.1 & 0.067 \\
\hline $\mathrm{PP} / \mathrm{CPP}-\mathrm{SO}_{3} \mathrm{H} / \mathrm{PANI} 1$ & 3343.3 & 56.9 & 0.441 & 3371 & 3417.9 & 69.0 & 0.76 \\
\hline $\mathrm{PP} / \mathrm{CPP}-\mathrm{SO}_{3} \mathrm{H} / \mathrm{PANI} 4$ & 3347.0 & 16.4 & 0.024 & 3366.5 & 3430.5 & 107.3 & 0.594 \\
\hline $\mathrm{PP} / \mathrm{CPP}-\mathrm{SO}_{3} \mathrm{H} / \mathrm{PANI} 5$ & 3351.5 & 26.9 & 0.185 & 3379.6 & 3422.3 & 90.7 & 2.324 \\
\hline
\end{tabular}

Abbreviations: CPP, chlorinated polypropylene; PANI, polyaniline; PP, polypropylene.

$\mathrm{N}-\mathrm{H} \cdots \cdots \mathrm{O} ;{ }^{25}$ another band, at $\sim 3420 \mathrm{~cm}^{-1}$, is attributed to the hydrogen-bonded $\mathrm{N}-\mathrm{H} \cdots \cdots \mathrm{Cl}$ and $\mathrm{N}-\mathrm{H} \cdots \cdots \mathrm{N}{ }^{20}$ With the aid of computer analysis, the curve-fitting spectra of the $\mathrm{N}-\mathrm{H}$ stretching region were produced for the $\mathrm{PP} / \mathrm{CPP} / \mathrm{PANI}$ and $\mathrm{PP} / \mathrm{CPP}-\mathrm{SO}_{3} \mathrm{H} / \mathrm{PANI}$ composites. An iterative least-squares computer program was used to obtain the best fit of the spectra of the N-H stretching region by varying the wave number $(v)$, width at half-height $\left(w_{1 / 2}\right)$ and area $(\mathrm{S})$ of several bands. There were two or three Gaussian bands in the N-H stretching region to be confirmed by the curve-fitting procedure. Typical examples are displayed in the inset of Figure $3 \mathrm{~b}$.

Table 2 lists the curve-fitting results for the spectra of the $\mathrm{N}-\mathrm{H}$ stretching region. The area (S2) of the band of $v 2$ is sufficiently small to be ignored compared with the areas of the bands of $v 1$ and $v 3$. The first band is attributed to the hydrogen-bonded N-H..... O the third band is attributed to the hydrogen-bonded $\mathrm{N}-\mathrm{H} \cdots \cdots \mathrm{Cl}$ and $\mathrm{N}-\mathrm{H} \cdots \cdots \mathrm{N}$. In the PP/CPP/PANI composite, the hydrogen-bonded $\mathrm{N}-\mathrm{H} \cdots \cdots \mathrm{O}$ is the intermolecular and intramolecular H-bonded interaction of PANI-DBSA. However, in the PP/CPP-SO ${ }_{3} \mathrm{H} / \mathrm{PANI}$ composites, the oxygen atom of the $\mathrm{H}$-bonded $\mathrm{N}-\mathrm{H} \cdots \cdots \mathrm{O}$ may be rooted in PANI-DBSA and $\mathrm{CPP}-\mathrm{SO}_{3} \mathrm{H}$, and it is impossible to separate the oxygen atom rooted in PANI-DBSA from that rooted in $\mathrm{CPP}-\mathrm{SO}_{3} \mathrm{H}$. Therefore, it is very difficult to quantitatively analyze the $\mathrm{H}$ bond. Nevertheless, the data listed in Table 2 show the effects of $\mathrm{CPP}-\mathrm{SO}_{3} \mathrm{H}$ on the $\mathrm{H}$ bond in the composites.

Table 2 shows that compared with that of the PP/CPP/PANI 0 composite, the wave number of the $\mathrm{H}$-bonded $\mathrm{N}-\mathrm{H} \cdots \cdots \mathrm{N}$ and $\mathrm{Cl}$ of the $\mathrm{PP} / \mathrm{CPP}-\mathrm{SO}_{3} \mathrm{H} / \mathrm{PANI}$ composites increases significantly; for example, the increment in PP/CPP-SO ${ }_{3} \mathrm{H} / \mathrm{PANI} 4$ is 17 wave numbers. However, the H-bonded $\mathrm{N}-\mathrm{H} \cdots \cdots \mathrm{O}$ band slightly shifts, as the sulfonating degree of $\mathrm{CPP}-\mathrm{SO}_{3} \mathrm{H}$ was seen to be only $1.53 \%$. These results show that the average strength of the H-bonded $\mathrm{N}-\mathrm{H} \cdots \cdots \mathrm{N}$ and $\mathrm{Cl}$ decreases and the $\mathrm{H}$-bonded band shifts to a higher wave number. ${ }^{26}$ The reason for this is that the $\mathrm{H}$-bonded $\mathrm{N}-\mathrm{H} \cdots \cdots \mathrm{N}$ and $\mathrm{Cl}$ are partially substituted by the $\mathrm{H}$-bonded $\mathrm{N}-\mathrm{H} \cdots \cdots$. the introduction of $-\mathrm{SO}_{3} \mathrm{H}$ into $\mathrm{CPP}$. From the shift of the $\mathrm{H}$-bonded band, the interaction between CPP and PANI-DBSA is strengthened by the introduction of $-\mathrm{SO}_{3} \mathrm{H}$ into $\mathrm{CPP}$. Hence, compared with the properties afforded by the PP/CPP/PANI 0 composite, the compatibility between PP and PANI-DBSA may be increased, the dispersion of PANI may be more homogeneous in the PP/CPP-SO ${ }_{3} \mathrm{H} / \mathrm{PANI} 4$ composite and the $\mathrm{PP} / \mathrm{CPP}-\mathrm{SO}_{3} \mathrm{H} / \mathrm{PANI} 4$ composite has a lower volume resistivity.

\section{UV-vis analysis of the PP/CPP-SO 3 H/PANI and PP/CPP/PANI composites}

Figure 4 shows the UV-vis spectra of the PP/CPP/PANI and PP/CPP$\mathrm{SO}_{3} \mathrm{H} / \mathrm{PANI}$ composites. The UV-vis spectra of the $\mathrm{PP} / \mathrm{CPP}-\mathrm{SO}_{3} \mathrm{H} /$ PANI composites are distinctly different from the PP/CPP/PANI composite spectrum, particularly at $\sim 880 \mathrm{~nm}$. The band at $\sim 880 \mathrm{~nm}$ is ascribed to the $\pi$-polaron transition of protonated PANI, which indicates the protonation and the degree of electron delocalization in PANI. ${ }^{27,28}$ The peaks were selected from this region, and the results are listed in Table 3.

From the data listed in Table 3, there is only one peak at $875 \mathrm{~nm}$ in the PP/CPP/PANI 0 and PP/CPP-SO ${ }_{3} \mathrm{H} / \mathrm{PANI} 1$ composites. In the $\mathrm{PP} / \mathrm{CPP}-\mathrm{SO}_{3} \mathrm{H} / \mathrm{PANI} 1$ composites, the $\mathrm{CPP}-\mathrm{SO}_{3} \mathrm{H}$ content is only $0.88 \%$; therefore, the effect of $\mathrm{CPP}-\mathrm{SO}_{3} \mathrm{H}$ on the $\pi$-polaron transition of protonated PANI is small. However, in other PP/CPP-SO ${ }_{3} \mathrm{H} / \mathrm{PANI}$ 


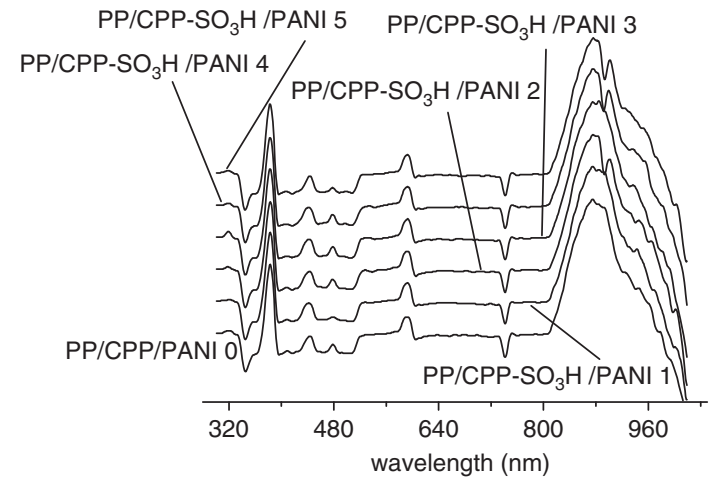

Figure 4 UV-vis spectra of the PP/CPP/PANI and PP/CPP-SO ${ }_{3} \mathrm{H} / \mathrm{PANI}$ composites. CPP, chlorinated polypropylene; PANI, polyaniline; PP, polypropylene; UV, ultraviolet.

Table 3 Peak-searching results of UV-vis spectra

\begin{tabular}{|c|c|c|}
\hline Sample code & Peak 1 (nm) & Peak 2 (nm) \\
\hline PP/CPP/PANI 0 & 875 & \\
\hline $\mathrm{PP} / \mathrm{CPP}-\mathrm{SO}_{3} \mathrm{H} / \mathrm{PANI} 1$ & 875 & \\
\hline PP/CPP-SO ${ }_{3} \mathrm{H} / \mathrm{PANI} 2$ & 876 & 901 \\
\hline $\mathrm{PP} / \mathrm{CPP}-\mathrm{SO}_{3} \mathrm{H} / \mathrm{PANI} 3$ & 875 & 885 \\
\hline $\mathrm{PP} / \mathrm{CPP}-\mathrm{SO}_{3} \mathrm{H} / \mathrm{PANI} 4$ & 875 & 899 \\
\hline $\mathrm{PP} / \mathrm{CPP}-\mathrm{SO}_{3} \mathrm{H} / \mathrm{PANI} 5$ & 876 & 901 \\
\hline
\end{tabular}

Abbreviations: CPP, chlorinated polypropylene; PANI, polyaniline; PP, polypropylene; UV, ultraviolet.

composites, there are two peaks: one at $\sim 875 \mathrm{~nm}$ and another at $\sim 895 \mathrm{~nm}$. This suggests that due to the introduction of $-\mathrm{SO}_{3} \mathrm{H}$ into $\mathrm{CPP}$, the degree of electron delocalization and the electrical conductivity of PANI-DBSA are increased and $\mathrm{CPP}-\mathrm{SO}_{3} \mathrm{H}$ facilitates the role of protonation. Therefore, the introduction of $-\mathrm{SO}_{3} \mathrm{H}$ can decrease the volume resistivity of the $\mathrm{PP} / \mathrm{CPP}-\mathrm{SO}_{3} \mathrm{H} / \mathrm{PANI}$ composites.

\section{Morphology of the composites}

Figure 5 shows SEM micrographs of the PP/CPP/PANI and PP/CPP$\mathrm{SO}_{3} \mathrm{H} / \mathrm{PANI}$ composites at 200 times the normal magnification. The white regions are insulating (that is, no PANI), and the black regions are conducting. The gray regions are transitions between insulating and conducting areas. The PANI content in the gray parts is lower than that in the black parts, and the darker area indicates a higher PANI content. ${ }^{19}$ In the SEM micrograph of PP/CPP/PANI 0 , the continuity of the conducting parts is bad and prone to be interrupted by insulating parts. This makes the material's ability to conduct electrons weaker. If the gray-scale intensity of the whitest region is defined to be 255 and that of the blackest region is defined to be 0 in the SEM image, ${ }^{19}$ Figure 5 can be digitally analyzed. The area of the range of the color intensity can be statistical. Although there are some parts that are gray in the intensity range of 135-255, the ability of these gray parts to conduct electrons is very weak. Hence, for statistical convenience, regions exhibiting a color range intensity of $0-135$ may be regarded as conducting.

Figure 2 shows that both areas of the conducting regions and volume resistivity vary with the $\mathrm{CPP}-\mathrm{SO}_{3} \mathrm{H}$ content. The trendline representing the area of the conducting regions versus the $\mathrm{CPP}-\mathrm{SO}_{3} \mathrm{H}$ content is contrary to that of the change in volume resistivity with $\mathrm{CPP}-\mathrm{SO}_{3} \mathrm{H}$ content. The area of the conducting regions first increases with increasing $\mathrm{CPP}-\mathrm{SO}_{3} \mathrm{H}$ content and reaches a maximum area when the $\mathrm{CPP}-\mathrm{SO}_{3} \mathrm{H}$ content is lower than $4.41 \%$; the area then decreases with a further increase in the $\mathrm{CPP}-\mathrm{SO}_{3} \mathrm{H}$ content. In other words, all of the composites exhibit a maximum area. This result may suggest that volume resistivity is greatly influenced by the area of the conducting regions (that is, the greater the area of the conducting regions, the lower the volume resistivity). Compared with PP/CPP$\mathrm{SO}_{3} \mathrm{H} / \mathrm{PANI} 4$, the conducting area of PP/CPP-SO ${ }_{3} \mathrm{H} / \mathrm{PANI} 5$ decreases significantly, and the dispersion of PANI-DBSA becomes worse; thus, its volume resistivity increases appreciably.

Figure 2 indicates that areas of the conducting regions of the PP/ $\mathrm{CPP}-\mathrm{SO}_{3} \mathrm{H} / \mathrm{PANI}$ composites are much greater than the area of the $\mathrm{PP} / \mathrm{CPP} / \mathrm{PANI} 0$ composite, and the volume resistivity of the PP/CPP$\mathrm{SO}_{3} \mathrm{H} / \mathrm{PANI}$ composites is much lower than that of the PP/CPP/PANI 0 composite. These results suggest that the introduction of $-\mathrm{SO}_{3} \mathrm{H}$ into CPP can increase the area of the conducting regions of the composites, improve compatibility between PP and PANI-DBSA and decrease volume resistivity of the composites.

\section{Wide-angle X-ray diffraction study}

The lamellar-like structure of PANI. Figure 6a shows the WAXD patterns of the PP/CPP/PANI and PP/CPP-SO 3 H/PANI composites using the first method over the range of $1.5-5^{\circ}$. The peak at $\sim 3^{\circ}$ is attributed to the lamellar-like structure of PANI-DBSA; $;^{18,29,30}$ the lamellar-like structure is also observed in the TEM micrograph. ${ }^{18}$ In $\mathrm{PP} / \mathrm{CPP} / \mathrm{PANI} 0$, there is only one peak at $\sim 3^{\circ}$. However, in the PP/ $\mathrm{CPP}-\mathrm{SO}_{3} \mathrm{H} / \mathrm{PANI}$ composite, there are two peaks: one at $\sim 3^{\circ}$ and another at $\sim 2.5^{\circ}$. These indicate that because of the introduction of $-\mathrm{SO}_{3} \mathrm{H}$ into $\mathrm{CPP}, \mathrm{CPP}-\mathrm{SO}_{3} \mathrm{H}$ is more easily inserted into the interspaces of PANI-DBSA, the layer distance of PANI-DBSA increases and the aggregating domains of PANI-DBSA become loose. The increasing layer distance is beneficial to the improvement in the dispersion of PANI-DBSA in the PP/CPP-SO ${ }_{3} \mathrm{H} / \mathrm{PANI}$ composites and decreases the volume resistivity of the composites. These effects agree with the results of the SEM measurement.

To quantify the influence of the introduction of $-\mathrm{SO}_{3} \mathrm{H}$ into the lamellar-like structure of PANI-DBSA in the PP/CPP/PANI composites, the WAXD curves in Figure 6a were fitted using the profilefitting program JADE 6.5. The profile-fitting results of the WAXD curves are listed in Table 4.

Compared with the parameters of the PP/CPP/PANI 0 composite's peak, the first peak of the PP/CPP-SO ${ }_{3} \mathrm{H} / \mathrm{PANI}$ composites shifts to a lower angle, and its layer distance increases. For example, the first peak of $\mathrm{PP} / \mathrm{CPP}-\mathrm{SO}_{3} \mathrm{H} / \mathrm{PANI} 4$ lies at $2.942^{\circ}$, and its layer distance is $30.01 \AA$. Moreover, the second peak of the PP/CPP-SO ${ }_{3} \mathrm{H} / \mathrm{PANI}$ composites lies at $\sim 2.47^{\circ}$, and its layer distance is $\sim 35.7 \AA$. These may explain why the volume resistivity of the $\mathrm{PP} / \mathrm{CPP}-\mathrm{SO}_{3} \mathrm{H} / \mathrm{PANI}$ composites is lower than that of the PP/CPP/PANI composite.

The crystalline structure. Figure $6 \mathrm{~b}$ shows the WAXD patterns of the $\mathrm{PP} / \mathrm{CPP} / \mathrm{PANI}$ and $\mathrm{PP} / \mathrm{CPP}-\mathrm{SO}_{3} \mathrm{H} / \mathrm{PANI}$ composites obtained using the second method over the range of $5-45^{\circ}$. In Figure $6 \mathrm{~b}$, the crystalline peaks at $\sim 14^{\circ}, 17^{\circ}, 18.5^{\circ}, 21^{\circ}$ and $21.8^{\circ}$ are attributed to the $\alpha$ crystal, and the crystalline peak at $\sim 16^{\circ}$ is attributed to the $\beta$-crystal. ${ }^{31}$

To quantify the influence of the introduction of $-\mathrm{SO}_{3} \mathrm{H}$ into the crystal structure of PP in the composites, the WAXD curves in Figure $6 \mathrm{~b}$ were fitted using the profile-fitting program JADE 6.5. The fitting range was chosen to be $9-26^{\circ}$ because almost all of the crystalline peaks fall within this range. Using Scherrer's law and the mass fraction crystal formula (for example, \% crystallinity 


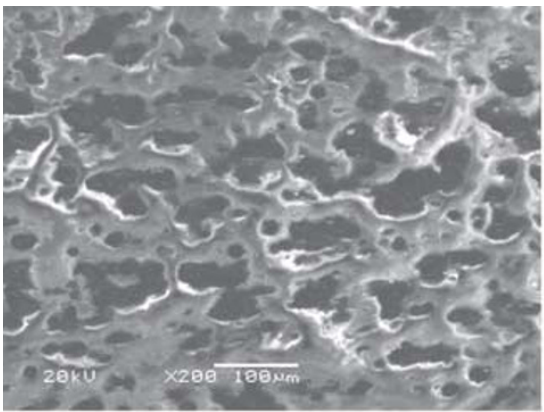

PP/CPP/PANI 0

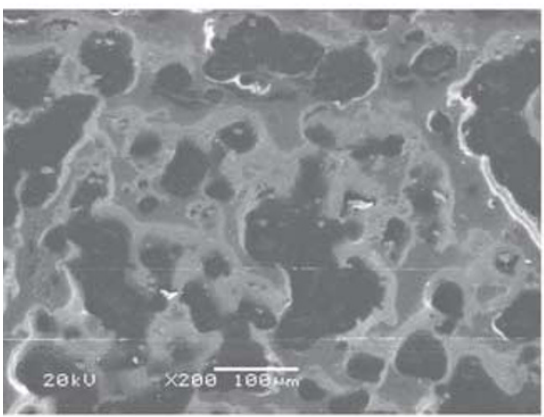

PP/CPP-SO ${ }_{3} \mathrm{H} / \mathrm{PANI} 2$

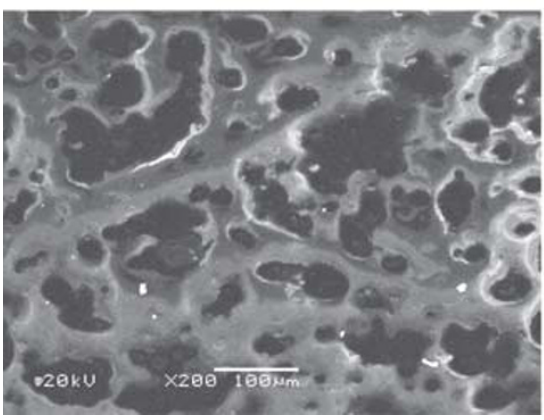

PP/CPP-SO ${ }_{3} \mathrm{H} / \mathrm{PANI} 4$

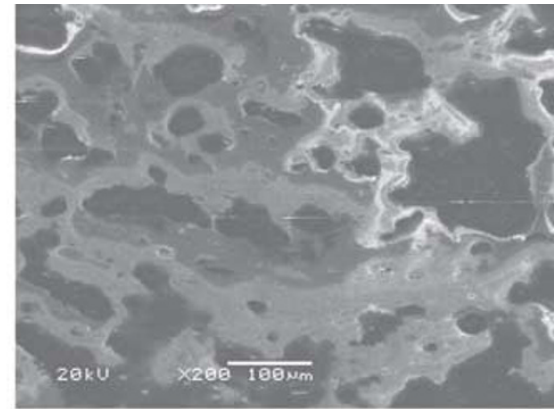

PP/CPP-SO ${ }_{3} \mathrm{H} / \mathrm{PANI} 1$

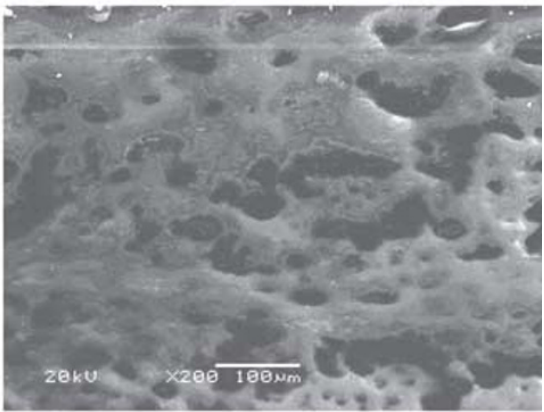

PP/CPP- $\mathrm{SO}_{3} \mathrm{H} / \mathrm{PANI} 3$

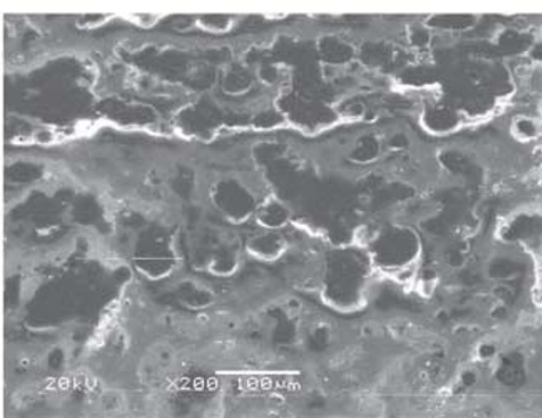

PP/CPP-SO ${ }_{3} \mathrm{H} / \mathrm{PANI} 5$

Figure 5 SEM micrographs of PP/CPP/PANI and PP/CPP-SO ${ }_{3} \mathrm{H} / \mathrm{PANI}$ composites. CPP, chlorinated polypropylene; PANI, polyaniline; PP, polypropylene; SEM, scanning electron microscopy.
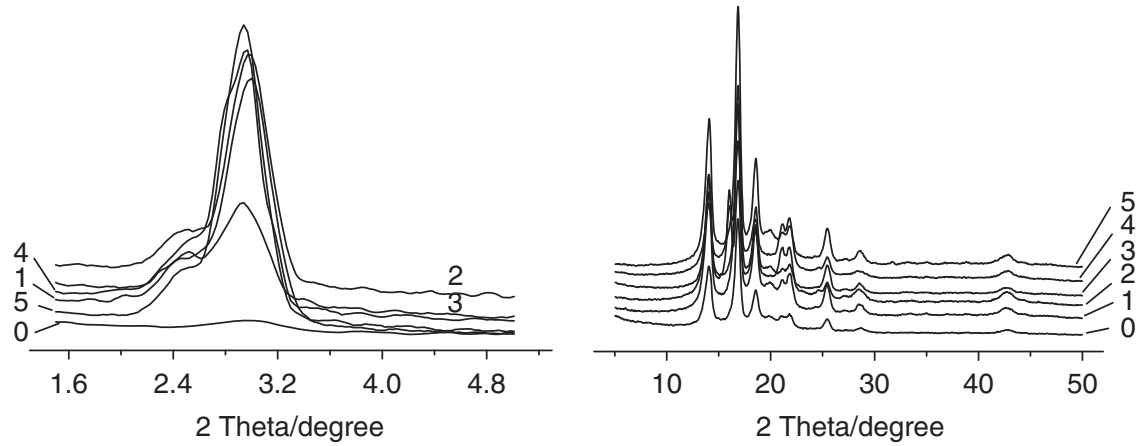

Figure 6 WAXD patterns of (0) PP/CPP/PANI O, (1) PP/CPP-SO ${ }_{3} \mathrm{H} / \mathrm{PANI}$ 1, (2) PP/CPP-SO ${ }_{3} \mathrm{H} / \mathrm{PANI}$ 2, (3) PP/CPP-SO ${ }_{3} \mathrm{H} / \mathrm{PANI} 3$, (4) PP/CPP-SO ${ }_{3} \mathrm{H} / \mathrm{PANI} 4$ and (5) PP/CPP-SO ${ }_{3} \mathrm{H} / \mathrm{PANI} 5$ in two angle ranges. CPP, chlorinated polypropylene; PANI, polyaniline; PP, polypropylene; WAXD, wide-angle X-ray diffraction. 
Table 4 Profile fitting results for WAXD curves of PP/CPP/PANI and PP/CPP-SO ${ }_{3} \mathrm{H} / \mathrm{PANI}$ composites in the range of $1.5-5$

\begin{tabular}{|c|c|c|c|c|c|c|c|c|}
\hline \multirow[b]{2}{*}{ Sample code } & \multicolumn{4}{|c|}{ Peak 1} & \multicolumn{4}{|c|}{ Peak 2} \\
\hline & $2 \theta_{1}\left(^{\circ}\right)$ & $D\left(A^{\circ}\right)$ & FWHM & $X S(A)$ & $2 \theta_{2}\left(^{\circ}\right)$ & $d(A \stackrel{\circ}{ })$ & FWHM & $X S(A)$ \\
\hline PP/CPP-SO ${ }_{3} \mathrm{H} / \mathrm{PANI} 1$ & 3.007 & 29.36 & 0.375 & 220 & 2.469 & 35.75 & 0.372 & 222 \\
\hline PP/CPP-SO ${ }_{3} \mathrm{H} / \mathrm{PANI} 2$ & 2.993 & 29.50 & 0.351 & 236 & 2.467 & 35.79 & 0.335 & 248 \\
\hline PP/CPP-SO ${ }_{3} \mathrm{H} / \mathrm{PANI} 3$ & 2.959 & 29.84 & 0.451 & 202 & 2.477 & 35.63 & 0.285 & 297 \\
\hline
\end{tabular}

Abbreviations: CPP, chlorinated polypropylene; PANI, polyaniline; PP, polypropylene; WAXD, wide-angle X-ray diffraction. ${ }^{[2]}$ WHM: width at half-height; $d$ : layer distance; XS: size of the lamellar-like structure.

Table 5 Structural parameters for PP/CPP/PANI and PP/CPP-SO ${ }_{3} \mathrm{H} / \mathrm{PANI}$ composite by means of WAXD

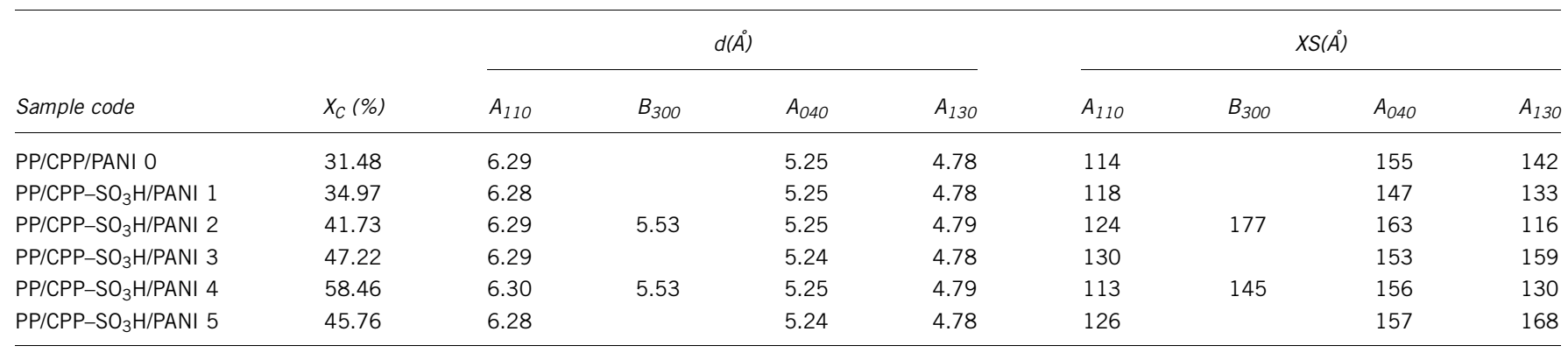

Abbreviations: CPP, chlorinated polypropylene; PANI, polyaniline; PP, polypropylene; WAXD, wide-angle X-ray diffraction.

$d$ : interplanar distance; XS: size of crystallite corresponding to appointed peak; A110, A040, and A130: the 110, 040 and 130 crystal face of $\alpha$-crystal respectively; B300: the 300 crystal face of $\beta$-crystal; $\mathrm{X}_{\mathrm{C}}$ : crystallinity index.

$=A_{c} /\left(A_{c}+A_{n}\right)$, where $A_{c}$ is the scattering from the sharp peaks of crystalline areas and $A_{n}$ the scattering from non-crystalline areas), the crystal size corresponding to the peaks and the percentage crystallinity of the composites was calculated. The profile-fitting results of the WAXD curves are listed in Table 5.

In Table 5 , the most evident change is that the $\mathrm{X}_{\mathrm{C}}$ of the PP/CPP$\mathrm{SO}_{3} \mathrm{H} / \mathrm{PANI}$ composites is higher than that of PP/CPP/PANI 0. Analogously, volume resistivity of the $\mathrm{PP} / \mathrm{CPP}-\mathrm{SO}_{3} \mathrm{H} / \mathrm{PANI}$ composites is higher than that of $\mathrm{PP} / \mathrm{CPP} / \mathrm{PANI} 0$. The $\mathrm{X}_{\mathrm{C}}$ of the PP/CPP$\mathrm{SO}_{3} \mathrm{H} / \mathrm{PANI}$ composites first increases with increasing $\mathrm{CPP}-\mathrm{SO}_{3} \mathrm{H}$ content and reaches a maximum $\mathrm{X}_{\mathrm{C}}$ when the $\mathrm{CPP}-\mathrm{SO}_{3} \mathrm{H}$ content is lower than $4.41 \%$; it then decreases with a further increase in the $\mathrm{CPP}-\mathrm{SO}_{3} \mathrm{H}$ content. The variation of $\mathrm{X}_{\mathrm{C}}$ with the $\mathrm{CPP}-\mathrm{SO}_{3} \mathrm{H}$ content is analogous to that of the volume resistivity with the $\mathrm{CPP}-\mathrm{SO}_{3} \mathrm{H}$ content. In accordance with the abovementioned results, the formation of high crystallinity in a host polymer is favorable for a decrease in volume resistivity. Compared with $\mathrm{PP} / \mathrm{CPP}-\mathrm{SO}_{3} \mathrm{H} / \mathrm{PANI} 4$, the $\mathrm{X}_{\mathrm{C}}$ of $\mathrm{PP} / \mathrm{CPP}-\mathrm{SO}_{3} \mathrm{H} / \mathrm{PANI} 5$ decreases significantly; therefore, its volume resistivity increases appreciably.

\section{CONCLUSIONS}

Chlorinated polypropylene was modified using sodium bisulfite as a sulfonating agent. The FTIR results show that $-\mathrm{SO}_{3} \mathrm{H}$ was successfully grafted onto CPP.

Compared with that of the PP/CPP/PANI composite, the volume resistivity of the $\mathrm{PP} / \mathrm{CPP}-\mathrm{SO}_{3} \mathrm{H} / \mathrm{PANI}$ composites clearly decreases. In the $\mathrm{PP} / \mathrm{CPP}-\mathrm{SO}_{3} \mathrm{H} / \mathrm{PANI}$ composites, the average strength of the $\mathrm{H}$ bonded $\mathrm{N}-\mathrm{H} \cdots \cdots \mathrm{N}$ and $\mathrm{Cl}$ decreases and is partially substituted by the $\mathrm{H}$-bonded $\mathrm{N}-\mathrm{H} \cdots \mathrm{N} \mathrm{O}$, and the interactional strength between PANI and CPP-SO ${ }_{3} \mathrm{H}$ increases due to the introduction of $-\mathrm{SO}_{3} \mathrm{H}$.
The UV-vis results show that due to the introduction of $-\mathrm{SO}_{3} \mathrm{H}$ into $\mathrm{CPP}$, the degree of electron delocalization and the electrical conductivity of PANI-DBSA increase, and $\mathrm{CPP}-\mathrm{SO}_{3} \mathrm{H}$ has the role of protonation agent in the $\mathrm{PP} / \mathrm{CPP}-\mathrm{SO}_{3} \mathrm{H} / \mathrm{PANI}$ composites. The analysis of the lamellar-like structure of PANI indicates that, compared with $\mathrm{CPP}, \mathrm{CPP}-\mathrm{SO}_{3} \mathrm{H}$ is more easily inserted into the interspaces of PANI-DBSA, the layer distance of PANI-DBSA increases and the aggregating domains of PANI-DBSA become loose. $\mathrm{CPP}-\mathrm{SO}_{3} \mathrm{H}$ can improve the crystallinity of the composites compared with $\mathrm{CPP}$. The introduction of $-\mathrm{SO}_{3} \mathrm{H}$ into $\mathrm{CPP}$ can increase the compatibility of the composites and the area of the conducting regions within the composites, and improve the dispersion of PANI and the conductive properties of the $\mathrm{PP} / \mathrm{CPP}-\mathrm{SO}_{3} \mathrm{H} / \mathrm{PANI}$ composites.

\section{CONFLICT OF INTEREST}

The authors declare no conflict of interest.

\section{ACKNOWLEDGEMENTS}

This paper is based on the results from the subject supported by the National Basic Research Program of China (2005CB623800).

1 Shirakawa, $\mathrm{H}$. The discovery of polyacetylene film -the dawning of an era of conducting polymers. Synthetic Met. 125, 3-10 (2001).

2 MacDiarmid, A. G. Synthetic metals: a novel role for organic polymers. Synthetic Met. 125, 11-22 (2001).

3 Heeger, A. J. Semiconducting and metallic polymers: the fourth generation of polymeric materials. Synthetic Met. 125, 23-42 (2001).

4 Koul, S., Chandra, R. \& Dhawan, S. K. Conducting polyaniline composite: a reusable sensor material for aqueous ammonia. Sensor Actuat. B Chem. 75, 151-159 (2001). 
5 Gerard, M., Chaubey, A. \& Malhotra, B. D. Application of conducting polymers to biosensors. Biosensors Bioelectronis 17, 345-359 (2002).

6 Jin, Z., Su, Y. \& Duan, Y. An improved optical pH sensor based on polyaniline. Sensor Actuat. B Chem. 71, 118-122 (2000).

7 Bernard, M. C., Hugot-Le Goff, A., Joiret, S. \& Phong, P. V. Polyaniline films for protection against corrosion. Synthetic Met. 119, 283-284 (2001).

8 Mirmohseni, A. \& Oladegaragoze, A. Anti-corrosive properties of polyaniline coating on iron. Synthetic Met. 114, 105-108 (2000).

9 Araujo, W. S., Margarit, I. C. P., Ferreira, M., Mattos, O. R. \& Lima Neto, P. Undoped polyaniline anticorrosive properties. Electrochimica Acta. 49, 1307-1312 (2001).

10 MacDiarmid, A. G. Polyaniline and polypyrrole: where are we headed? Synthetic Met. 84, 27-34 (1997).

11 Barra, G. M. O., Leyva, M. E., Soares, B. G., Mattoso, L. H. \& Sens, M. Electrically conductive, melt-processed polyaniline/EVA blends. J. Appl. Poly. Sci. 82, 114-123 (2001).

12 Luzny, W., Kaniowski, T. \& Pron, A. Structural and transport properties of thermally processable conducting polymer: polyaniline protonated with diphenyl phosphate. Polymer 39, 475-483 (1998).

13 Pron, A., Luzny, W. \& Laska, J. Thermally processable polyaniline protonated with diphenyl phosphate -preparation and structural aspects. Synthetic Met. 80, 191-193 (1996).

14 Fryczkowski, R., Slusarczyk, C. \& Fabia, J. Structure and conducting properties of thermoplastic composites of polypropylene and polyaniline protonated in solid state. Synthetic Met. 156, 310-317 (2006).

15 Cao, Y., Smith, P. \& Heeger, A. J. Counter-ion induced processibility of conducting polyaniline and of conducting polyblends of polyaniline in bulk polymers. Synthetic Met. 48, 91-97 (1992).

16 Laska, J., Zak, K. \& Pron, A. Conducting blends of polyaniline with conventional polymers. Synthetic Met. 84, 117-118 (1997)

17 Laska, J., Pron, A., Zagorska, M., Lapkowski, S. \& Lefrant, S. Thermally processable conducting polyaniline. Synthetic Met. 69, 113-115 (1995).

18 Passiniemi, P., Laakso, J., Osterholm, H. \& Pohl, M. TEM and WAXS characterization of polyaniline/PP fibers. Synthetic Met. 84, 775-776 (1997).

19 Yang, L., Chen, J. Y. \& Li, H. L. Investigation on the microstructure and the electric property of poly(propylene)/chlorinated poly(propylene)/poly(aniline) composites. J. Appl. Poly. Sci. 111, 988-997 (2009).
20 Yang, L., Chen, J. Y. \& Li, H. L. Effects of chlorinated polypropylene on the hydrogenbond and electric property of polypropylene/chlorinated polypropylene/polyaniline composites: FTIR analysis. Polym. Eng. Sci. 49, 462-470 (2009).

21 Cai, R. L., Qiu, Y., Wang, W. L., Zhang, L. C. \& Hu, X. M. The research on technology and process of lining-up soluble sulphur blue through catalysis and sulphonating. Anhui Chem. Industry 34, 32-34 (2008).

22 Li, R. D., Ge, J. J., Zhang, G. C. \& He, W. D. Study on the sulfonating conditions of alkylphenol polyxyethylene ether sulfonate synthesized by the method of Streck. J. Xi'an Shiyou University (Natural Science Edition) 25, 57-60 (2010).

23 Taipalus, R., Harmia, T. \& Zhang, M. Q. The electrical conductivity of carbon-fibrereinforced polypropylene/polyaniline complex-blends: experimental characterization and modeling. Compos. Sci. Technol. 61, 801-814 (2001).

24 Weiss, R. A., Ashish, S., Willis, C. L. \& Pottick, L. A. Block copolymer ionomers: 1. Synthesis and physical properties of sulphonated poly(styrene-ethylene/butylene-styrene). Polymer 32, 1867-1874 (1991).

25 Wang, F. C., Feve, M., Lam, T. M. \& Pascault, J. P. FTIR analysis of hydrogen bonding in amorphous linear aromatic polyurethanes. I. Influence of temperature. J. Polym. Sci. Poly. Phys. 32, 1305-1313 (1994).

26 Wang, F. C., Feve, M., Lam, T. M. \& Pascault, J. P. FTIR analysis of hydrogen bonding in amorphous linear aromatic polyurethanes. II. Influence of styrene solvent. J. Polym. Sci. Poly. Phys. 32, 1315-1320 (1994).

27 Ren, B., Huang, H., Liu, S. Q. \& Yu, H. Z. Spectra analysis of PAn/PVA conductive composites. Chinese J. Spectrosc. Lab. 20, 165-168 (2003).

28 Potje-Kamloth, K., Polk, B. J., Josowicz, M. \& Janata, J. Doping of polyaniline in the solid state with photogenerated triflic acid. Chem. Mater. 14, 2782-2787 (2002).

29 Levon, K., Ho, K. H., Zheng, W. Y., Laakso, J., Taka, T. \& Osterholm, J. E. Thermal doping of polyaniline with dodecylbenzene sulfonic acid without auxiliary solvents. Polymer 36, 2733-2738 (1995).

30 Pan, W., Yang, S. L., Li, G. \& Jiang, J. M. Electrical and structural analysis of conductive polyaniline/polyacrylonitrile composites. Eur. Polym. J. 41, 2127-2133 (2005).

31 Obadal, M., Cermak, R. \& Stoklasa, K. Tailoring of three-phase crystalline systems in isotactic poly(propylene). Macromol. Rapid. Comm. 26, 1253-1257 (2005). 